\title{
7T MRI Loop Antenna for Carotid Imaging
}

Hinge, Lars; Mortensen, Nicolai; Zhurbenko, Vitaliy; Boer, Vincent O.; Wang, Wenjun

\section{Published in:}

Proceedings of 2020 European Microwave Conference

Link to article, DOI:

10.23919/EuMC48046.2021.9338233

Publication date:

2021

Document Version

Peer reviewed version

Link back to DTU Orbit

\section{Citation (APA):}

Hinge, L., Mortensen, N., Zhurbenko, V., Boer, V. O., \& Wang, W. (2021). 7T MRI Loop Antenna for Carotid Imaging. In Proceedings of 2020 European Microwave Conference (pp. 1007-1010). IEEE.

https://doi.org/10.23919/EuMC48046.2021.9338233

\section{General rights}

Copyright and moral rights for the publications made accessible in the public portal are retained by the authors and/or other copyright owners and it is a condition of accessing publications that users recognise and abide by the legal requirements associated with these rights.

- Users may download and print one copy of any publication from the public portal for the purpose of private study or research.

- You may not further distribute the material or use it for any profit-making activity or commercial gain

- You may freely distribute the URL identifying the publication in the public portal

If you believe that this document breaches copyright please contact us providing details, and we will remove access to the work immediately and investigate your claim. 


\title{
7T MRI Loop Antenna for Carotid Imaging
}

\author{
Lars Hinge $^{\# 1}$, Nicolai Mortensen ${ }^{\# 2}$, Vitaliy Zhurbenkoo ${ }^{\# 3}$ Vincent O. Boer ${ }^{* 4}$ Wenjun Wang $\# 5$ \\ \#Electromagnetic Systems, Department of Electrical Engineering, \\ DTU Elektro, Technical University of Denmark, Kgs. Lyngby, Denmark \\ *Danish Research Centre for Magnetic Resonance, Centre for Functional and Diagnostic Imaging and Research, \\ Copenhagen University Hospital Hvidovre, Hvidovre, Denmark \\ $\left\{{ }^{1}\right.$ s154349, ${ }^{2}$ s154332\}@ @student.dtu.dk, ${ }^{3}$ vz@elektro.dtu.dk ${ }^{4}$ vincentob@drcmr.dk ${ }^{5}$ wewan@elektro.dtu.dk
}

\begin{abstract}
Tesla Magnetic resonance imaging (MRI) is one of the most promising candidates for detecting carotid failure prematurely. To be able to use the technology efficiently, it is necessary to use separate, specialised antennas that can be applied to the body region of interest. Here a fractionated loop antenna is simulated and fabricated to determine optimal characteristics for 7T MRI carotid imaging application. A coilformer for applying the antenna to the carotid region is built, and EM simulations of the antenna are verified by testing the antenna in a 7T MRI scanner. On a saltwater phantom, it is determined that $60 \%$ of the peak signal is seen at the approximate position of the carotids, which means the antenna is an efficient transmit and receive element for a neck array coil.

Keywords - Magnetic resonance imaging, High-field MRI,
\end{abstract} Microwave antennas, Simulation

\section{INTRODUCTION}

For 7T high field magnetic resonance imaging (MRI) applications, it is necessary to have transceiver antennas close to the body of the patient in order to get the best signal to noise ratio. A 7T field corresponds to a frequency of around $298 \mathrm{MHz}$, which means a regular loop antenna would be electrically large and thus induce heat into a patients body. To reduce this effect [1] and [2] use a coil design with capacitors spread out along the antenna to electrically shorten the antenna, while keeping its physical size. This design is used and improved, and [3] is used as inspiration to shape the loop to the body for better SNR. In order to allow practical testing with advantageous shaping, a coilformer is build that gives mechanical support to the antennas. The aim is to build an antenna that can be used for a high-performance array coil for neck imaging of carotid arteries and the spinal cord.

\section{Methods}

In order to compare and have a measure of the antenna efficiency, a parameter is introduced given by $\frac{B_{1_{+}}}{\sqrt{S A R_{\text {max }}}} . B_{1_{+}}$ or $B_{1_{-}}$[T] is a measure of rotation of the magnetic field quantified at depth, which is desired to be as high as possible in MRI antennas, as the B field is what the MRI scanner uses to transmit and receive. The specific absorption ratio SAR $\left[\frac{\mathrm{W}}{\mathrm{kg}}\right]$ is a measure of how much energy is deposited in the dielectric (body). So if this value is low, the antenna can be run with higher input power within safety regulations. The SAR measurements are averaged over $10 \mathrm{~g}$ for all future purposes with $S A R_{\text {max }}$ being the maximum $10 \mathrm{~g}$ SAR hot-spot in a given simulation. Combining these two gives the antenna performance measure of $\frac{B_{1}}{\sqrt{S A R_{\max }}}$, which is desired to be as high as possible at the carotids.

CST simulations are made with varying parameters for the antennas. To be able to determine which parameter changes increase the performance of the antenna, six different plots are created as is done in [4]. Evaluation of these allows changing one parameter with every simulation run and afterwards determine what value gave the antenna the best performance. The specific parameters that are to be simulated are the values of the capacitors which intersect the antenna, and the overlap between adjacent antennas to reduce cross-talk for when a full array is to be populated. In CST the antennas are placed $1 \mathrm{~cm}$ above the human skin phantom with dimensions in $\mathrm{x}, \mathrm{y}$ and $\mathrm{z}$ equal to the longest side of the antenna $+10 \%$, and the $\mathrm{H}$-field, E-field, and loss in the phantom simulated at $298 \mathrm{MHz}$.

Afterwards, the fabricated antennas $B_{1_{+}}$at the carotid region is determined in a $7 \mathrm{~T}$ MRI scanner, thus determining both if the simulations are valid and if the antenna is applicable.

\section{DESIGN}

The design phase can broadly be divided into the sections: Electromagnetic modelling, fabrication of coilformer and fabrication of the antenna.

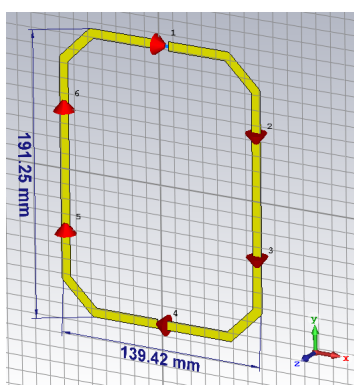

(a)

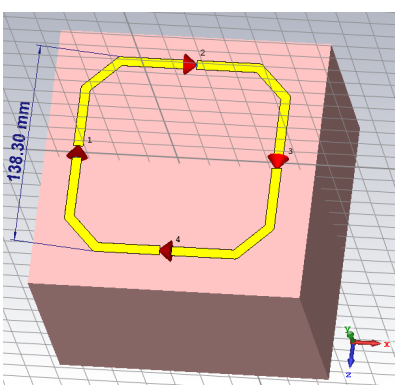

(b)
Fig. 1. Stating models for the coming simulations: (a) Rectangular loop; (b) Small square loop

\section{A. Electromagnetic Simulations}

All electromagnetic (EM) simulations are done in CST Microwave studio 2017, and are normalized to $1 \mathrm{~W}$ accepted power into the antennas for SAR and $B_{1_{+}}$results. Two kinds of loop antennas are investigated, of which the first is described 

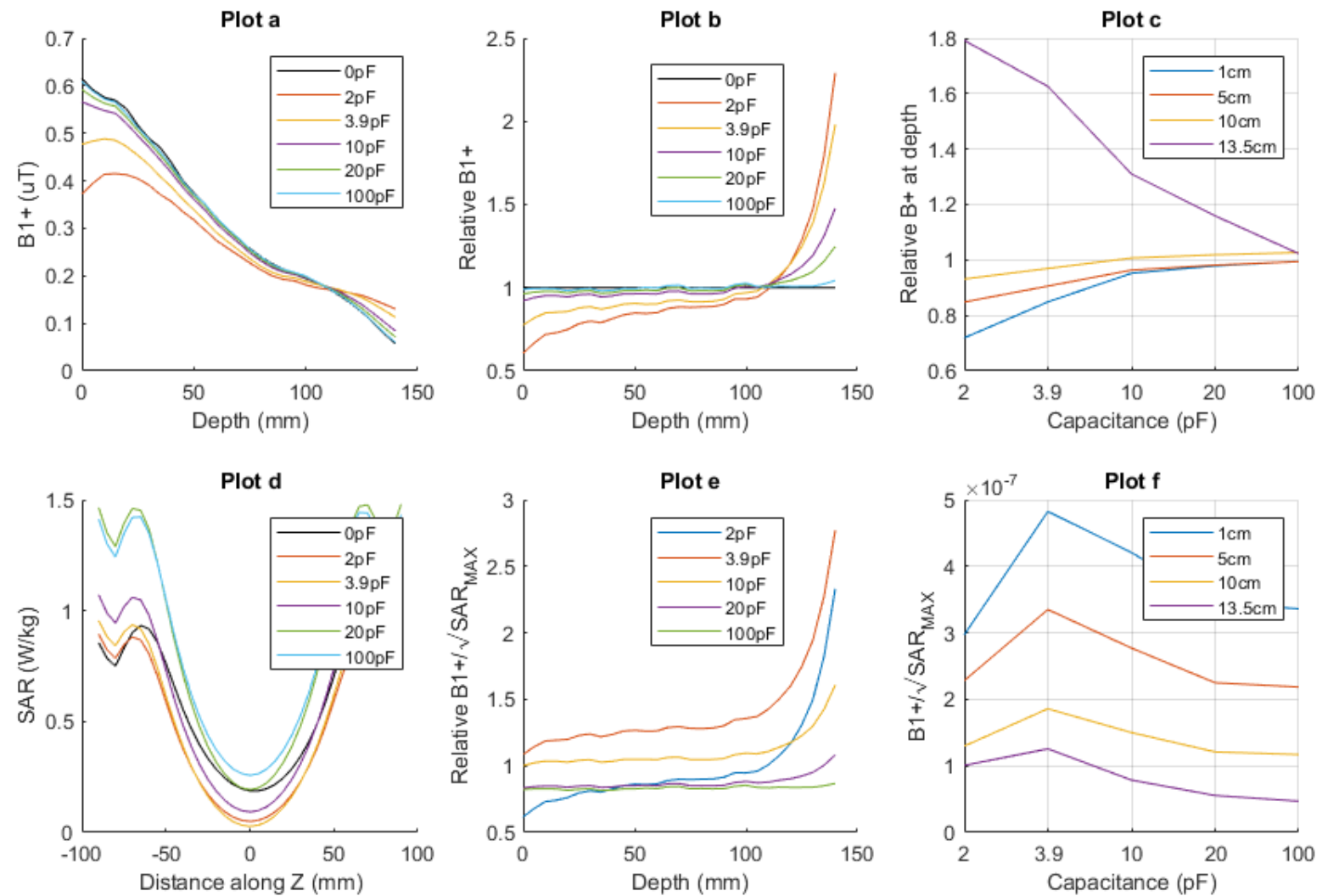

Fig. 2. Plotted results of CST simulation of small square antenna using different capacitances. a) Shows amount of $B_{1+}$ through the phantom along center line. b) Shows the same as 'a' but relative to a coil of same size without capacitances (Black). c) Relative $B_{1}+$ vs. capacitances plotted at different depths. d) Amount of $S A R_{\max }$ along top of center line along Z-axis of phantom. e) Relative $\frac{B_{1}}{\sqrt{S A R_{\max }}}$ through the phantom f) $\frac{B_{1}+}{\sqrt{S A R_{\max }}}$ vs. capacitances plotted at different depths, showing the superiority of using $3.9 \mathrm{pF}$ capacitors.

in [1], [2] and has dimensions $191 \times 139 \mathrm{~mm}$, while the second shorter, square version of it is $138 \times 138 \mathrm{~mm}$. The rectangular antenna is intersected with five and the square antenna with three capacitors to keep the length of each segment approximately equal. The main reason for investigating their differences is that a smaller antenna would better fit the proposed coilformer. Both are printable loop antennas and the simulation models can be seen in Figure $1 \mathrm{~b}$ and $1 \mathrm{a}$.

First, both loops are simulated with varying values of intersecting capacitors in order to determine what capacitance is needed for optimal operation. Post-processing algorithms are then used to generate SAR and $B_{1_{+}}$information, which is exported in $5 \times 5 \mathrm{~mm}$ grid-size files.

The resulting plots for the smaller square antenna are shown in Figure 2 where Plot a shows better $B_{1_{+}}$for higher intersecting capacitances and Plot $d$ suggests better SAR with lower values. A higher $\frac{B_{1}}{\sqrt{S A R_{\max }}}$ in the f-plot than the corresponding results for the bigger antenna (not shown here), is the reason for disregarding the larger antenna. From the same plot $\mathrm{f}$ it is determined that $3.9 \mathrm{pF}$ capacitances yield best performance at the desired depth.

In order to reduce interference of antennas lying close together for the potential application as part of an array, a
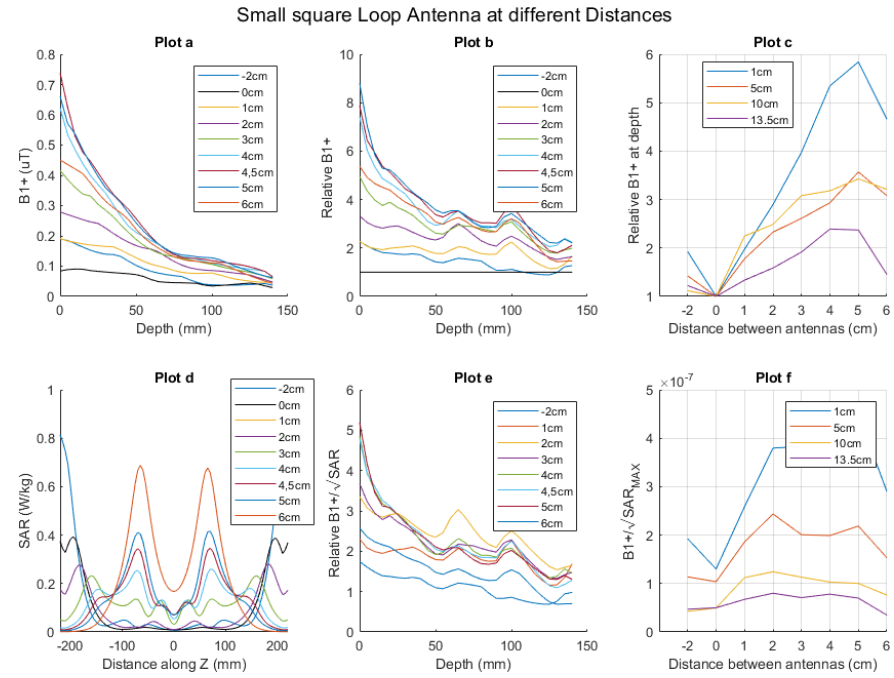

Fig. 3. Plotted results of CST simulation of three small loop antennas at different distances. a) Shows amount of $B_{1_{+}}$through the phantom along center line for the different distances. b) Shows the same as 'a' but as relative to no distance between them (Black) (i.e. overlapping conductor). c) Relative $B_{1}$ vs. distances plotted at different depths into the phantom. d) Amount of $S A R_{\max }$ along top of center line along $\mathrm{Z}$-axis of phantom. e) Relative $\frac{B_{1}}{\sqrt{S A R_{\max }}}$ through the phantom $\mathrm{f}$ ) Relative $\frac{B_{1}}{\sqrt{S A R_{\max }}}$ vs. distances plotted at different depths. 
simulation setup is run with three small square antennas at varying distances to each other, to determine what the best distance is for the $\frac{B_{1}}{\sqrt{S A R_{\max }}}$ ratio. If this parameter were not properly taken care off, cross-talk between antennas in a populated array would vastly reduce the signal to noise ratio. The results are intended to guide the placement of the loop antennas on a coilformer for full population, which will be necessary for use on a real patient. Figure 3 shows the results from this simulation. All lines are taken along the centre line of the middle antenna of the three. The most noteworthy results are that the $B_{1_{+}}$is strongest at the depth of the carotids if the antennas are overlapped with $4-5 \mathrm{~cm}$ (Fig. 3, Plot c). For optimal $\frac{B_{1}}{\sqrt{S A R_{\max }}} 2 \mathrm{~cm}$ would already be enough however (Fig. 3, Plot f).

Lastly, a simulation is run with 6 loop antennas populating a coilformer, shaped approximately to its form as seen in Figure $5 \mathrm{a}$, in order to estimate combined effectiveness. Figure 4 shows a cross-sectional $\frac{B_{1}}{\sqrt{S A R_{\max }}}$ view of the neck area from this simulation where the four cross sections are chosen to highlight the max. value. The focus carotid area is around $\mathrm{Z}=70 \mathrm{~mm}-90 \mathrm{~mm}$ at $\mathrm{X}=\mathrm{Y}=0$.

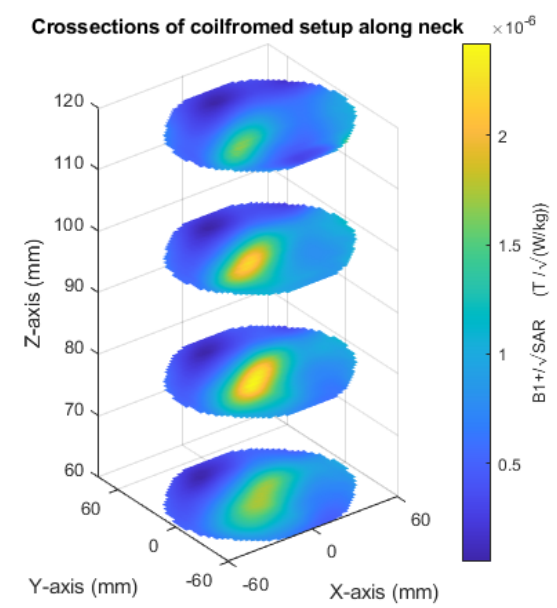

Fig. 4. Simulated $\frac{B_{1}}{\sqrt{S A R_{\max }}}$ cross sections along the carotid of a phantom.

\section{B. Fabrication of Coilformer}

In order to provide stable support for the antennas during testing, a plastic shape "coilformer" is fabricated. This is done by segmenting the coilformer 3D-file obtained from [5] into 22 pieces, 3D printing them one at a time and glueing them together. Stabilisation components are added to enable the coilformer to stand on a flat surface. Figure $5 b$ shows the finished coilformer, and Table 1 lists some physical characteristics.
Table 1. Coilformer physical characterisation

\begin{tabular}{l|ll}
\hline Parameter & Value & Unit \\
\hline Width (x) & 194 & $\mathrm{~mm}$ \\
Height (y) & 227 & $\mathrm{~mm}$ \\
Depth (z) & 474 & $\mathrm{~mm}$ \\
Max. tested load & 5 & $\mathrm{~kg}$
\end{tabular}

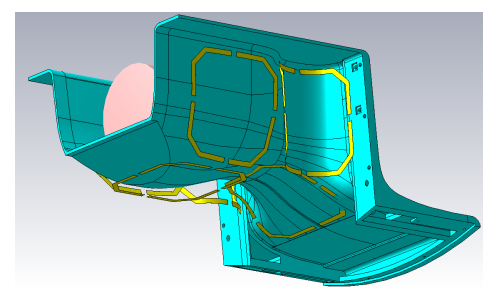

(a)

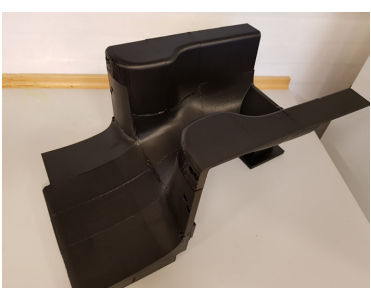

(b)
Fig. 5. The Coilformer; (a) as model in CST; (b) fully fabricated and spray-painted

\section{Antenna fabrication}

The layout of the antenna, which can be seen in Figure 6a, is etched on an RT/duroid 6002 PTFE Ceramic 6in x 6in plate. This material had the lowest loss (Tan $\delta @ 10 \mathrm{GHz}$ $=0.0015)$ of the available materials while being sufficiently flexible to allow fitting antennas to the uneven surface of the coilformer. Conductor squares are placed on the bottom side of the PCB to reduce the effect of the 7T MRI field on the lumped components of the antenna. The thin copper layer and the flexible board allow fitting to the coilformer, as seen in Figure 6b. A simple matching circuit is created using two capacitors in series and one inductor in parallel. A simulation for the loop antenna is made where the voltage across the connecting $3.9 \mathrm{pF}$ capacitors is tested, and at $300 \mathrm{MHz}$ the voltage across the capacitor is around $900 \mathrm{~V}$, with an input power of $8 \mathrm{~kW}$, which is below the $1500 \mathrm{~V}$ rating of the used components. After fabrication, the antennas are fitted to the coilformer. For matching, a plastic bag is filled with 5 litres $3 \mathrm{~g} / \mathrm{l}$ saltwater which is used as the load. The antennas are matched using non-magnetic $1500 \mathrm{~V}$ capacitors and air-wound inductors, and they are given non-magnetic BNC connectors, such that the antenna is entirely non-magnetic and thus able to withstand the $7 \mathrm{~T}$ of the MRI scanner.

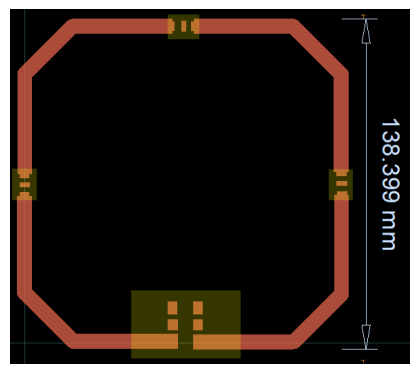

(a)

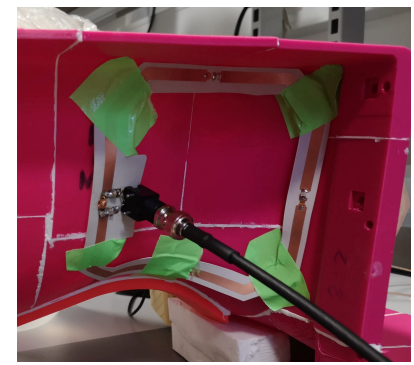

(b)
Fig. 6. The fabricated antenna (a) as layout ready for printing; (b) printed and attached to the coilformer to optimal carotid accessibility 


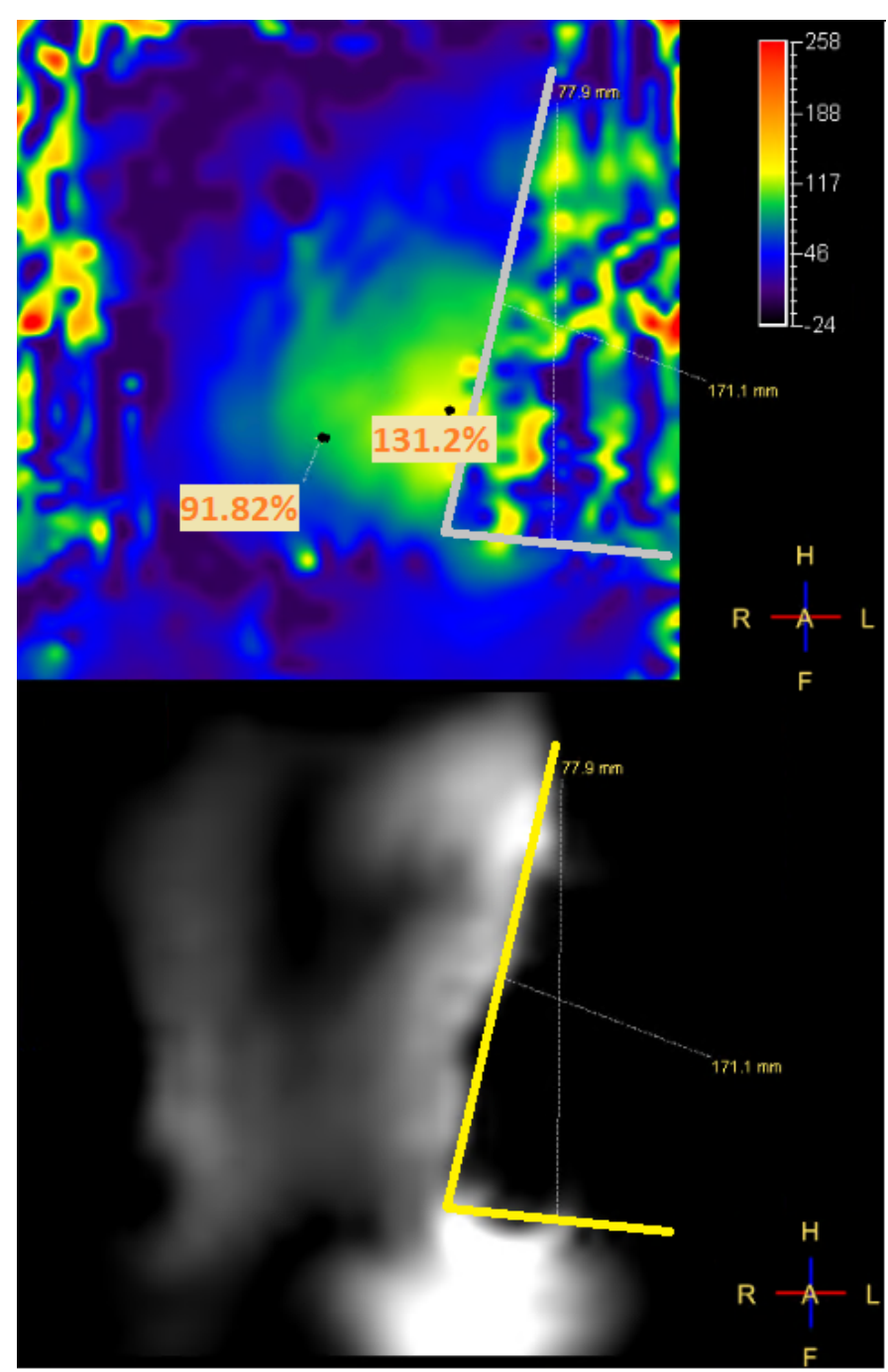

Fig. 7. Sample results from 7T MRI scanner test with the outline of the coilformer as L-shape where the phantom lies to the left; (Top) Coronal $B_{1}+$ map with labels at the carotid region and centre of the antenna; (Bottom) Corresponding magnitude image showing the transmission pattern of the antenna.

\section{TESTING AND Results}

Figure 7 shows the results of testing the single antenna in the 7T MRI scanner attached to the coilformer: A coronal $B_{1_{+}}$ map through the same saltwater neck-phantom as was used for matching. The left side of the yellow/grey lines in the figure is where the patient would be lying and is thus the area of interest. The top part of the figure shows the $B_{1_{+}}$field strength plotted in relative values, which means the difference between points is of interest. The marked position denoting $131.2 \%$ is at the centre of the antenna and thus the maximum value of $B_{1_{+}}$, while the position with $91.82 \%$ is an approximation of the main carotid region. From there, it is determined that approximately $60 \%$ of the generated magnetic field reaches the carotids. The bottom of the figure shows the corresponding magnitude image and displays the outline of the phantom too.

\section{CONCLUSION}

It has been shown through EM simulations that the fractionated loop antenna has increased $\frac{B_{1_{+}}}{\sqrt{S A R_{\text {max }}}}$ and $B_{1_{+}}$ or $B_{1}$ compared to a non-fractionated version of it, and that a smaller version of the loop has even better $\frac{B_{1_{+}}}{\sqrt{S A R_{\max }}}$. Further, it has been determined through simulation that the best capacitor value to intersect the antenna is $3.9 \mathrm{pF}$ and that an antenna overlap of $4-5 \mathrm{~cm}$ in an array would yield the best performance. A single antenna has been fabricated, and a coilformer has been built from multiple 3D printed pieces to create a device for holding the antenna close to a human neck, namely the carotid artery. On this coilformer, the antenna has been tuned and matched to a saltwater phantom load, and imaging experiments in a 7T MRI scanner have been conducted. The results show that approximately $60 \%$ of the generated magnetic field reaches the carotids. Further work will be aimed at constructing a full 8-channel array using the coil to optimise transmit and receive characteristics in the neck region to allow more detailed investigation of plaques in the carotids arteries.

\section{ACKNOWLEDGMENT}

The author wishes to thank the Cohen-Adad et al. group [5] for giving us access to their 3D file for the coilformer. Also, thanks to the institute for providing all the used materials.

\section{REFERENCES}

[1] M. Vossen et al., "A radiofrequency coil configuration for imaging the human vertebral column at 7 T," Journal of Magnetic Resonance, vol. 208, pp. 291-297, 2011.

[2] O. Kraff et al., "An eight-channel phased array RF coil for spine MR imaging at 7 T," Investigative Radiology, vol. 44, pp. 734-740, 2009.

[3] M. Picirelli et al., "Carotid artery imaging at 7T: SNR improvements using anatomically tailored surface coils," in ISMRM 2008, Jan. 2008.

[4] A. Raaijmakers et al., "The fractionated dipole antenna: A new antenna for body imaging at 7 Tesla : The fractionated dipole antennas," Magnetic Resonance in Medicine, vol. 75, pp. 1366-1374, 2016.

[5] J. Cohen-Adad et al., "32-channel RF coil optimized for brain and cervical spinal cord at $3 \mathrm{~T}: 32 \mathrm{ch}$ head/c-spine coil at $3 \mathrm{~T}$," Magnetic Resonance in Medicine, vol. 66, p. spcone, 2011. 